\title{
The synthesis of metallic and semiconducting nanoparticles from reactive melts of precursors
}

Cite this: J. Mater. Chem. A, 2014, 2, 570

Received 25th July 2013

Accepted 9th September 2013

DOI: $10.1039 / c 3 t a 12900 d$

www.rsc.org/MaterialsA

\section{Introduction}

This review aims to highlight a promising class of reactions that potentially provide a simple and scalable route to nanomaterials. These processes, which we shall refer to as melt reactions, are solventless reactions carried out by heating a precursor, often under an inert atmosphere, to bring about its decomposition. The melt approach has been successful in preparing a broad range of nanomaterials including metals, metal oxides, and metal chalcogenides. A wide range of morphologies including

${ }^{a}$ School of Materials, University of Manchester, Manchester M13 9PL, UK. E-mail: Paul. O'Brien@manchester.ac.uk

${ }^{b}$ Schools of Materials and of Chemistry, University of Manchester, Manchester M13 9PL, UK spheres, ${ }^{1,2}$ nanorods, ${ }^{3,4}$ nanowires,${ }^{5-7}$ nanofabrics, ${ }^{5}$ and nanodisks ${ }^{3,8,9}$ have been prepared using this process.

The dominant chemical approach to nanoparticle synthesis is currently hot-injection. ${ }^{10}$ There is also considerable interest in heating-up reactions, which have attracted attention because of their scalability. ${ }^{\mathbf{1 1}}$ In comparison, melt reactions are simpler and potentially easier to scale up than most other routes. Melt reactions are solventless: this gives the melt approach a potential economic and environmental advantage over both hot-injection and heating-up approaches which use high boiling point solvents and precursors.

An interesting feature of these reactions is that they are usually "self capping". Capping ligands play an important role in nanoparticle synthesis: passivating the particle's surface, controlling the rate of growth and, in some cases, influencing

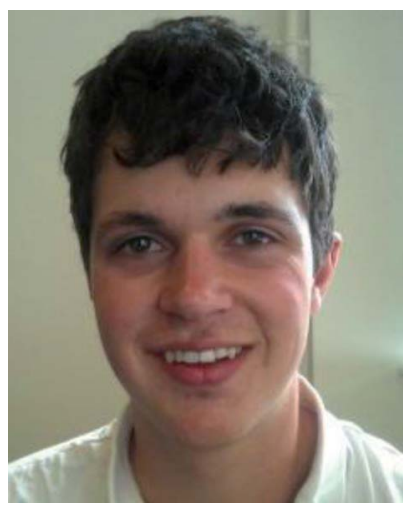

Edward Lewis received his MChem degree from the University of Oxford in 2011. He is working towards a PhD in nanoscience at the University of Manchester under the supervision of Sarah Haigh and Paul O'Brien. His research involves the development of techniques for in situ observation of nanoparticle growth.

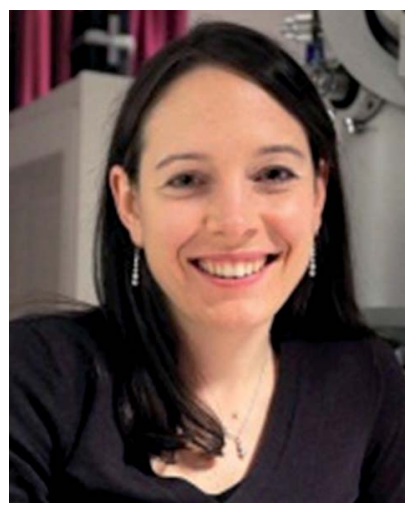

Sarah Haigh is a Lecturer in Material Science at the University of Manchester. She received her MEng degree in Material Science from the University of Oxford in 2004 and her D.Phil degree in Advanced Microscopy in 2008 in the same department working under the supervision of Prof. Angus Kirkland and Prof. John Hutchison. She was a postdoctoral research fellow working with JEOL UK until moving to the University of Manchester in 2010. Her current research focuses on using high resolution imaging and elemental analysis to study a range of novel materials systems, including graphene based high mobility transistors, mixed-metal nanoparticle catalysts and high performance alloys. In 2013 she was awarded the Institute of Materials, Minerals and Mining Silver Medal for outstanding contribution to the broad field of materials science. 
the shape of particles formed. In a typical hot-injection synthesis the solvent into which the precursor is injected acts as the capping ligand. In melt reactions, ligands produced during the precursor's decomposition can cap the nanoparticles. Removing the need for solvents has both economic and environmental benefits.

Another interesting feature of melt reactions is the proposed relationship between precursor structure and nanoproduct shape, most convincingly observed in the thermolysis of layered thiolate precursors. ${ }^{\mathbf{8 1 2 , 1 3}}$ This approach is a relatively new, and largely unexplored, way to control nanocrystal shape. Some researchers also claim that solventless methods reduce interparticle collisions, ensuring growth occurs solely by monomer addition. ${ }^{3,6}$ Consequently, this approach has the potential to give high quality monodisperse products. ${ }^{3,6}$

A wide range of single-source precursors have already been developed for use in metal-organic chemical vapour deposition (MOCVD) and hot-injection syntheses. ${ }^{\mathbf{1 4 , 1 5}}$ While some of these precursors have been used in melt reactions, a huge number of promising molecules have yet to be investigated. Fig. 1 shows the structures of some of the ligands that have been used as precursors in melt reactions. We hope that this review will stimulate further investigations into this class of reactions. There is great potential to explore a more diverse range of precursor chemistry and gain a better understanding of how the reaction conditions and precursor structure influence the size, shape, and composition of the nanoproducts. Ultimately this approach could prove to be commercially important,

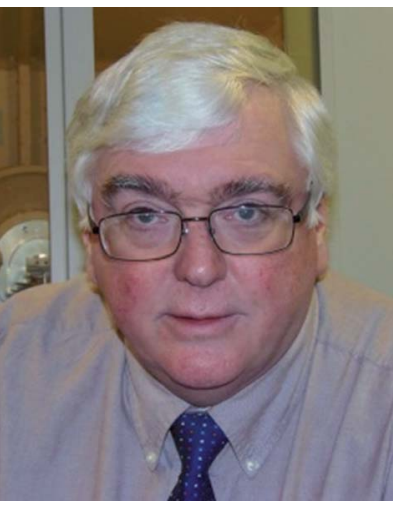

Paul O'Brien is Chair of Inorganic Materials Chemistry in the Schools of Chemistry and of Materials at the University of Manchester; he was Research Dean 2000-2003, Head of the School of Chemistry 2002-09 and is now Head of the School of Materials 2011. He held academic positions at Chelsea, Queen Mary and Imperial Colleges in the University of London. External appointments have included: Vice President of the RSC 2009-11, visiting Professor at Georgia Tech 1996-99, visiting Fellow Magdalen College Oxford 2009 and Distinguished Fellow at the Institute for Advanced Studies Durham 2011. He has received distinguished alumni awards: the Potts Medal (Liverpool) and the A. G. Evans Memorial Medal Lecture (Cardiff). He was also awarded the Kroll and Sir Colin Humphreys Medals of the IOMMM and the first Peter Day Award from the RSC. His research centres on developing new chemical processes for thin films and nanoparticles; especially of chalcogenides. He holds honorary D.Scs. from both the Universities of Zululand and Liverpool. In 2002 he founded Nanoco, now listed on AIM/LSE. In May 2013 he was elected a Fellow of the Royal Society London. a)<smiles>[R]C(=O)O[Hg]</smiles>

b)<smiles>[R]S</smiles>

e)<smiles>S=C(S)c1ccccc1</smiles>

c)<smiles>[R]OC(=S)S[2H]</smiles><smiles>[R]n1nnnc1S</smiles>

d)<smiles>[R]N([R])C(=S)S</smiles>

Fig. 1 Some of the ligands used as precursors in melt reactions: carboxylic acids (a), thiols (b) xanthates (c), dithiocarbamates (d), dithiocarboxylates (e), and thiotetrazoles (f).

providing a simple, cheap, and scalable way to mass produce nanoparticles.

This review aims to summarise all the examples to date of solventless nanoparticle synthesis using single-source selfcapping precursors. The review is divided into two parts; the first concerning elemental (metals) and the second compound materials such as sulfides or oxides.

\section{Metals}

\subsection{Metal nanocrystals from the salts of carboxylic acids}

Silver. To the best of our knowledge Abe and co-workers were the first to demonstrate the melt approach in their synthesis of

a)

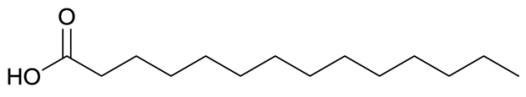

b)

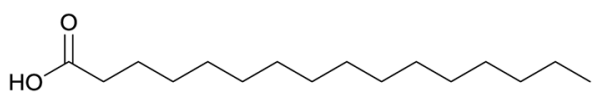

c)

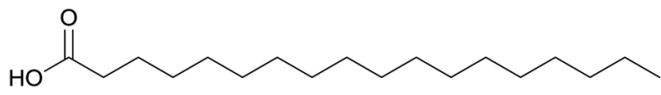

d)

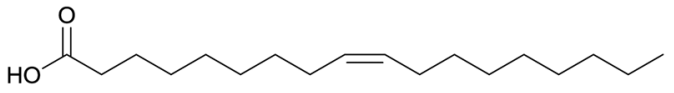

e)

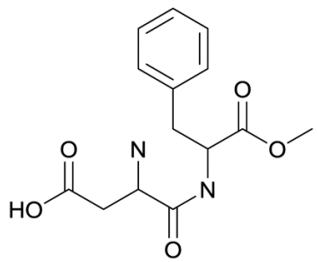

Fig. 2 Myristic- (a), palmitic- (b), stearic- (c) and oleic-acid (d), and aspartame (e) have been used to synthesise silver nanoparticles. 
silver nanoparticles. ${ }^{1}$ The silver salts of myristic-, stearic-, and oleic-acid (Fig. 2a, c, and d) were heated in a nitrogen atmosphere at $250{ }^{\circ} \mathrm{C}$ forming silver nanoparticles capped by alkylate ligands. ${ }^{\mathbf{1 1 6}}$ The particles were dispersible in non-polar liquids such as hexane, cyclohexane and toluene suggesting the alkyl chains of the capping ligands point outwards. ${ }^{\mathbf{1 , 1 6}}$

The spherical silver nanoparticles were assembled into hexagonally close packed two-dimensional arrays by spreading a toluene suspension of the nanoparticles on a water surface. ${ }^{\mathbf{1 6}}$ The silver core size was found to be independent of the organic acid used. The separation between nanoparticles was dependent on the alkyl chain length; longer chains resulted in larger gaps between particles. This correlation supports the particles being self-capped with the precursor fatty acids.,16

Further investigation of the silver nanoparticles formed by heating the silver salts of myristic-, stearic-, and oleic-acid under nitrogen at $250{ }^{\circ} \mathrm{C}$ for 1-2 hours showed that the products from all three precursors were silver nanoparticles with a mean diameter of $4.7 \pm 0.6 \mathrm{~nm} .{ }^{17}$ High resolution TEM imaging revealed that only $\mathrm{ca} .2 \%$ of the particles were single crystals and the majority contained multiple twin defects. ${ }^{17}$ The fatty acid used in the precursor caps the nanoparticles, preventing aggregation. It was found that these capping ligands could be removed by heating at $210{ }^{\circ} \mathrm{C}$ in air. Thin films of silver can be produced by coating a surface with these nanoparticles and heating it to $250{ }^{\circ} \mathrm{C}^{.17}$

In a similar reaction, Lee et al. heated the silver salt of oleic acid (Fig. 2d), to produce silver nanoparticles. ${ }^{18,19}$ However, their experiments were carried out at low pressures: they transferred the dry silver complex to a Pyrex tube, flushed it with nitrogen and then sealed it at 0.3 Torr. The temperature was gradually increased at $2{ }^{\circ} \mathrm{C} \mathrm{min}^{-1}$ and then maintained at 290 ${ }^{\circ} \mathrm{C}$ for an hour before cooling back to room temperature. ${ }^{18}$ Thermogravimetric analysis (TGA) shows that the silver-oleate decomposes at $287^{\circ} \mathrm{C}^{18}$ Decomposition is believed to occur by homolytic cleavage of the metal-carboxylate bond, forming free radicals. ${ }^{19}$ The oleate molecules act as capping ligands, hindering addition to the surface, causing slow steady growth. TEM images show a very narrow size distribution and interparticle separations of $2 \mathrm{~nm} .^{18}$

This separation is significantly less than twice the approximate length of the oleate ligand $(1.75 \mathrm{~nm})$ suggesting interdigitation. Energy dispersive X-ray spectroscopy (EDX) confirmed that the nanocrystals were pure silver. ${ }^{\mathbf{1 8}}$

Yang et al. produced a series of fatty acid stabilized silver nanoparticles with different length alkyl chains. ${ }^{20}$ The particles were synthesised by heating the dry silver salts of fatty acids at $250{ }^{\circ} \mathrm{C}$ in a nitrogen atmosphere for 2 hours. A series of six acids were used: -OOC- $\left(\mathrm{CH}_{2}\right)_{m-2}-\mathrm{CH}_{3}(m=8,10,12,14,16$, and 18). In all cases the spherical silver nanoparticles produced were found to be $4.7 \pm 0.6 \mathrm{~nm}$ in diameter. ${ }^{20}$

The silver salt of aspartame (Fig. 2e) has also been used in the solventless synthesis of silver nanoparticles. ${ }^{21}$ Heating in a furnace under a nitrogen atmosphere produces spherical silver nanoparticles. Particle size depends on the temperature used; $185{ }^{\circ} \mathrm{C}$ for 10 minutes gave $5 \pm 2 \mathrm{~nm}$ particles whilst $200{ }^{\circ} \mathrm{C}$ for 10 minutes gave $45 \pm 10 \mathrm{~nm}$ particles. TGA reveals a mass loss starting at $185^{\circ} \mathrm{C}$ and ending at $200{ }^{\circ} \mathrm{C}$, infra red spectroscopy (IR) reveals that this process corresponds to the loss of the ester group. It is believed that the formaldehyde molecule released forms $\mathrm{H}_{2}$ and $\mathrm{CO}$, two strongly reducing molecules, and these species are key in reducing $\operatorname{Ag}(\mathrm{I})$ to $\mathrm{Ag}(0)$. The larger particle size at $200{ }^{\circ} \mathrm{C}$ is explained as a consequence of the higher concentration of these reducing molecules. ${ }^{21}$

Silver-carboxylate decomposition in the presence of an amine has also been investigated. ${ }^{22,23}$ Silver-myristate (Fig. 2a) in triethylamine $\left(\mathrm{NEt}_{3}\right)$ decomposes at the very low temperature of $80{ }^{\circ} \mathrm{C}$ to produce highly monodisperse silver nanoparticles, $4.4 \pm 0.2 \mathrm{~nm}$ in diameter. The precursor is insoluble in the tertiary amine. It is proposed that an intermediate silvermyristate-amine adduct forms and this intermediate undergoes rapid thermal decomposition, forming myristate capped silver nanoparticles dispersed in the amine. Gas chromatography and mass spectrometry confirm that the silver nanoparticles formed are capped only with myristate and not the amine, the interparticle separations seen in TEM images also lend support to the view that the particles are myristate capped. ${ }^{22}$ All other reactions described in this review involve a solid precursor being heated in a furnace to produce nanoparticles. At first glance this reaction appears to be different as it was performed in a liquid. However, the liquid amine acts neither as a solvent for the precursor, nor as a capping agent for the nanoparticles formed. The myristate is a solid that undergoes solventless thermolysis producing nanoparticles capped by groups originating solely from the precursor. The amine's only role is that of a catalyst, making a reaction that was previously performed at $250{ }^{\circ} \mathrm{C}$ take place at $80{ }^{\circ} \mathrm{C} .{ }^{22}$

The approach to silver nanoparticle synthesis described in this section may find applications in the electronics industry. The European Union's waste electrical and electronic equipment (WEEE) legislation banned the use of lead in consumer electronics. ${ }^{24}$ This legislation prompted a shift in the electronics industry from the use of tin/lead solders towards lead-free alternatives. ${ }^{24}$ Electrically conductive adhesives (ECAs), consisting of a polymer resin combined with a metal filler, are one alternative to lead based solders. ${ }^{25}$ Silver nanoparticles have been incorporated into such ECAs, and the low temperature sintering of $\mathrm{Ag}$ nanoparticles can lead to highly conductive adhesives. $^{26,27}$

The silver salts of fatty acids are known to form silver nanoparticles in melt reactions. ${ }^{1}$ These reactions have been used in the development of new lead-free solders. ${ }^{28,29}$ When using conductive epoxy based adhesives in printed electronics, high conductivity and short sintering times are both desirable properties. Wong et al. describe the sintering of a composite containing silver flakes. ${ }^{28}$ During sintering silver carboxylates on the surface of the flakes decomposes to form silver nanoparticles. These nanoparticles sinter at temperatures well below the bulk melting point of silver, rapidly forming metallic bridges between the flakes, improving conductivity. ${ }^{28}$ The lowered melting point of silver nanoparticles has also been exploited in the related area of screen printed thick films. ${ }^{29}$ The silver salt of palmitic acid (Fig. 2b) was heated under nitrogen at 250-270 ${ }^{\circ} \mathrm{C}$ for $90-120$ minutes, producing silver nanoparticles 
ranging in size from 5-50 $\mathrm{nm}$. This silver nanopowder was combined with an organic vehicle to form a conductive paste. This paste can be screen printed onto a substrate and then sintered. It is possible to sinter the paste at very low temperatures: $250-300{ }^{\circ} \mathrm{C}$, compared to $650-800{ }^{\circ} \mathrm{C}$ required for pastes containing silver micropowders. The resulting films show impressive resilience to high temperatures and high currents. ${ }^{29}$

The low sintering temperatures of silver nanoparticles mean that melt reactions that yield silver nanoparticles may find applications in the electronics industry. However, some concerns remain regarding the toxicity and environmental impact of silver nanoparticles. ${ }^{30}$

Gold. When $\mathrm{Au}\left(\mathrm{C}_{13} \mathrm{H}_{27} \mathrm{COO}\right)\left(\mathrm{PPh}_{3}\right)$ is heated for 5 hours at $180{ }^{\circ} \mathrm{C}$ under a nitrogen atmosphere, spherical gold nanoparticles, $23 \pm 5 \mathrm{~nm}$ in diameter, are formed. ${ }^{31}$ Infrared spectroscopy (IR), X-ray photoelectron spectroscopy (XPS), and ${ }^{1} \mathrm{H}$ nuclear magnetic resonance (NMR) of the nanoparticles show that the gold cores are capped with myristate $\left(\mathrm{C}_{13} \mathrm{H}_{27} \mathrm{COO}\right)$ and small amounts of $\mathrm{PPh}_{3}$. The liquid by-product is found to contain myristic acid and the gold(I) complex $\left[\mathrm{Au}\left(\mathrm{PPh}_{3}\right)_{2}\right]^{+}$. It is proposed the reduction of $\mathrm{Au}(\mathrm{I})$ is accompanied by elimination of $\mathrm{PPh}_{3}$ that reacts with the precursor complex to give $\left[\mathrm{Au}\left(\mathrm{PPh}_{3}\right)_{2}\right]\left[\mathrm{C}_{13} \mathrm{H}_{27} \mathrm{COO}\right]$. This complex does not decompose and provides myristate ligands to cap the gold nanoparticles. When the same reaction is carried out under atmospheric conditions $\mathrm{Au}$ nanoparticle yield becomes quantitative as the $\left[\mathrm{Au}\left(\mathrm{PPh}_{3}\right)_{2}\right]\left[\mathrm{C}_{13} \mathrm{H}_{27} \mathrm{COO}\right]$ by-product is no longer formed. It is believed that eliminated $\mathrm{PPh}_{3}$ is oxidised to $\mathrm{OPPh}_{3}$. Increased size and dispersity (70-180 $\mathrm{nm}$ ) are seen and particle shapes becomes non-spherical due to the absence of myristate and $\mathrm{PPh}_{3}$ to stabilize the gold nanoparticles. ${ }^{31}$ This reaction demonstrates that the atmosphere under which a melt is performed can influence the product morphology.

Nickel. Nickel oleate can be thermally decomposed in a nitrogen atmosphere to give Ni nanoparticles the size of which is strongly temperature dependent. ${ }^{32}$ At temperatures less than $333^{\circ} \mathrm{C}$ no significant amounts of nanoparticles are produced, at $330^{\circ} \mathrm{C}$ for 1 hour a trace of nanoparticles (with average diameter of $5 \mathrm{~nm}$ ) are formed, at $350{ }^{\circ} \mathrm{C}$ for an hour all precursor forms nanoparticles with an average size of $5.1 \mathrm{~nm}$, at $380{ }^{\circ} \mathrm{C}$ the average size increases to $5.9 \mathrm{~nm}$, and with $400{ }^{\circ} \mathrm{C}$ an average diameter of $6.6 \mathrm{~nm}$ is seen. The temperature also influences the crystal phase of the nanoproducts; face-centred cubic (fcc) $\mathrm{Ni}$ is seen at $350{ }^{\circ} \mathrm{C}$, at $380{ }^{\circ} \mathrm{C}$ a small amount of the hexagonal close packed (hcp) phase is also seen and by $400{ }^{\circ} \mathrm{C}$ hcp is more prevalent than fcc. No nickel oxide is seen, even after prolonged exposure to air, and it is believed that this is because the oleate capping layer inhibits oxidation. ${ }^{32}$

\subsection{Metal nanocrystals from the salts of thiols}

Silver. The silver salts of thiols have been used as melt precursors for silver nanocrystals. ${ }^{8}$ An interesting feature of solventless synthesis is the possibility for the crystal structure of the solid precursor to influence the morphology of the nanoproducts. ${ }^{13}$ Silver-dodecanethiolate is a layered solid which when heated at $180{ }^{\circ} \mathrm{C}$ for 2 hours in a nitrogen atmosphere forms silver nanodisks, with a diameter of about $16.1 \mathrm{~nm}$ and a thickness of $2.3 \mathrm{~nm}^{8}$ It is postulated that these highly anisotropic products are a consequence of the layered nature of the precursor. Upon heating $\operatorname{Ag}(\mathrm{I})$ is reduced to $\mathrm{Ag}(0)$ with the corresponding oxidation of the thiol to a radical, leading to the formation of a disulfide by-product (Fig. 3). The metal atoms form a planar structure that is closely related to the layered structure of the precursor. Interplanar diffusion of these silver atoms will be hindered by organic chains and the large separation between metallic layers (34.6 ̊). Therefore, particle growth is primarily through in-plane diffusion of silver atoms and is consequently anisotropic (see Fig. 4). ${ }^{8}$ This approach represents a method of control not available in solvent based synthesis: influencing the nanoproduct's shape through the solid precursor's crystal structure. ${ }^{13}$

Bismuth. Thiolates have also been used as precursors in the solventless synthesis of bismuth nanostructures. ${ }^{12,33,34}$ As we have already seen in the synthesis of silver nanodisks, layered thiolate precursors can produce unusual product morphologies. ${ }^{8}$ The bismuth thiolate $\mathrm{Bi}\left(\mathrm{SC}_{12} \mathrm{H}_{25}\right)_{3}$ was shown by X-ray diffraction to have a layered structure with interlayer spacing of $31.49 \AA$, a distance corresponding to approximately twice the thiolate chain length. Thermolysis of this precursor was carried out at $90{ }^{\circ} \mathrm{C}$ under vacuum. ${ }^{12}$ The nanoproducts produced were shown to consist of only Bi (although heating at $250{ }^{\circ} \mathrm{C}$ under $\mathrm{N}_{2}$ gives $\mathrm{Bi}_{2} \mathrm{~S}_{3}$, see Section 3.2). The morphology of the products depends upon reaction time. Thermolysis at $90{ }^{\circ} \mathrm{C}$ for 2 hours produces amorphous Bi nanofilms; these films are only $0.6 \mathrm{~nm}$ ( 2 or 3 atoms) thick. ${ }^{12}$ At longer reaction times crystalline $\mathrm{Bi}$ nanorhombi begin to form on the film. After 5 hours at $90{ }^{\circ} \mathrm{C}$

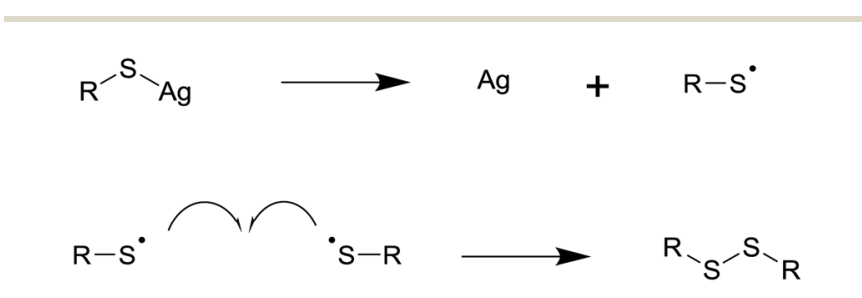

Fig. 3 The decomposition of silver thiolates to form silver metal and a disulfide by-product.

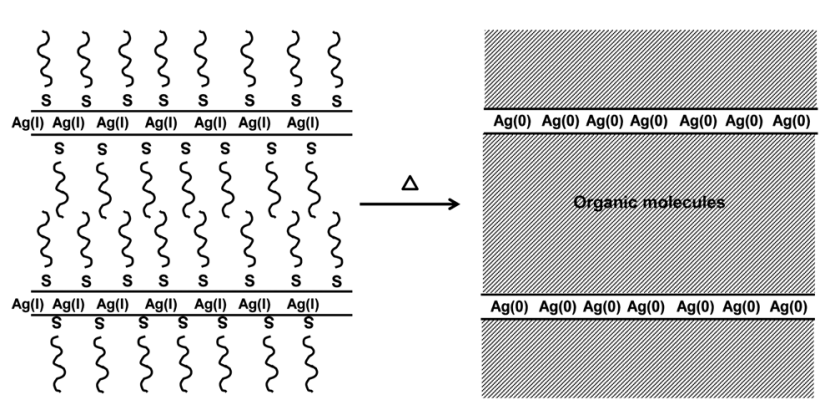

Fig. 4 Decomposition of layered thiolate precursors is believed to lead to thin layers of metal atoms separated by thick layers of organic molecules. In plane diffusion of metal atoms is encouraged while interplane diffusion is limited, leading to asymmetric growth. This has been seen for both silver and bismuth thiolates. ${ }^{8,12}$ 
only layers of nanorhombi are present. The individual nanorhombi have side lengths of $21.5 \mathrm{~nm}$, thicknesses of $0.9 \mathrm{~nm}$, and they form quasi close packed two dimensional arrays. ${ }^{12}$ These observations give an insight into the mechanism of solventless decomposition for layered precursors. The Bi layer apparently inherits the layered structure of the precursor, forming an amorphous nanofilm. Subsequently crystallisation can occur by diffusion of metal atoms. However, the large interlayer separation and the presence of the long alkyl chains between layers means that the diffusivity is highly anisotropic and diffusion is effectively confined to intralayer motion. In this manner layered crystalline rhombi are formed. ${ }^{12}$ It is possible that $\mathrm{Ag}$ nanodisks are formed by a similar mechanism, but due to the higher reaction temperature $\left(180^{\circ} \mathrm{C}\right)$ crystallisation is more rapid making it difficult to detect the nanofilm intermediate. ${ }^{8}$ This work demonstrated the first synthesis of Bi nanoparticles below $100{ }^{\circ} \mathrm{C}$ without the use of a reducing agent; illustrating the potential of solventless synthesis to provide gentle and facile routes to nanoparticles. ${ }^{12,33}$ As with silver thiolates it is presumed that this redox reaction involves the reduction of $\mathrm{Bi}(\mathrm{III})$ to $\mathrm{Bi}(0)$ and the oxidation of thiols to radicals which combine to form disulfides. ${ }^{33,34}$ The same $\mathrm{Bi}\left(\mathrm{SC}_{12} \mathrm{H}_{25}\right)_{3}$ precursor has been decomposed at higher temperatures (140$180{ }^{\circ} \mathrm{C}$ for 3 minutes under vacuum) to give large spherical Bi nanoparticles. ${ }^{34}$ In this study it was found that increasing the decomposition temperature reduced nanoparticle size and improved shape regularity. ${ }^{34}$ Wang et al. also studied $\mathrm{Bi}\left(\mathrm{SC}_{12} \mathrm{H}_{25}\right)_{3}$ as a precursor for the solventless synthesis of $\mathrm{Bi}$ nanoparticles. ${ }^{33}$ They were able to control product morphology by incorporating additional capping agents into their solid precursor. A precursor with an excess of dodecanethiol (DT) was heated under $\mathrm{N}_{2}$ for 10 hours at 120 or $135{ }^{\circ} \mathrm{C}$ to produce $\mathrm{Bi}$ nanodisks. When polyvinylpyrrolidone (PVP) was added to the $\mathrm{Bi}\left(\mathrm{SC}_{12} \mathrm{H}_{25}\right)_{3}$ precursor, $\mathrm{Bi}$ nanospheres were produced by heating under $\mathrm{N}_{2}$ for an hour at $105{ }^{\circ} \mathrm{C}$. It is suggested that the layered nature of the DT precursor may play a role in directing the formation of nanodisks while the PVP precursor probably forms a colloidal system upon thermolysis leading to isotropic growth of spherical particles. ${ }^{33}$ An alternative suggestion is that nanodisks arise because DT binds strongly to the faces of $\mathrm{Bi}$, while PVP doesn't adsorb preferentially on any face. ${ }^{33}$ Wang et al. report that increasing the reaction temperature produces larger Bi nanoparticles, in contrast to Carotenuto's work discussed earlier. ${ }^{33,34}$

Gold. Nakamoto et al. used the single-source precursor $\left[\mathrm{C}_{14} \mathrm{H}_{29}\left(\mathrm{CH}_{3}\right)_{3} \mathrm{~N}\right]\left[\mathrm{Au}\left(\mathrm{SC}_{12} \mathrm{H}_{25}\right)_{2}\right]$ in the first solventless synthesis of gold nanoparticles. ${ }^{35}$ The precursor was heated at $180{ }^{\circ} \mathrm{C}$ under a nitrogen atmosphere for 5 hours. TEM images show that the nanoparticles produced are spherical in shape and have diameters ranging from 5 to $50 \mathrm{~nm}$, with an average diameter of $26 \mathrm{~nm}$. XPS was used to confirm that the nanoparticles consist entirely of the $\operatorname{Au}(0)$ oxidation state, with no $\operatorname{Au}(\mathrm{I})$. XPS and elemental analysis show that there is no $\mathrm{S}$ or $\mathrm{N}$ present, demonstrating that thiolates and amines play no role in capping the nanoparticles. The ${ }^{1} \mathrm{H}$ NMR spectra show that the gold cores are capped by alkyl chains. ${ }^{35}$ The organic liquid byproduct of this nanoparticle synthesis was found to consist primarily of the disulfide $\left(\mathrm{C}_{12} \mathrm{H}_{25} \mathrm{~S}\right)_{2}$. Trimethylamine $\left(\mathrm{NMe}_{3}\right)$ was detected in the gaseous products. It is proposed that the reaction proceeds by elimination of the thiolate radical, reducing $\mathrm{Au}(\mathrm{I})$ to $\mathrm{Au}(0)$ and leading to the formation of the disulfide by-product. ${ }^{35}$ This nanoparticle synthesis is achieved without the need of a reducing agent, a solvent, or a capping agent. It is suggested that the disulfide by-product plays a stabilizing role as far larger particle sizes were seen when gold(I) benzenethiolate precursors were used. ${ }^{35}$

A further study of this system focused on the role of the ammonium ion; a series of precursors $\left[\mathrm{RN}\left(\mathrm{CH}_{3}\right)_{3}\right]\left[\mathrm{Au}\left(\mathrm{SC}_{12} \mathrm{H}_{12}\right)_{2}\right]$, where $\mathrm{R}=\mathrm{C}_{8} \mathrm{H}_{17}, \mathrm{C}_{12} \mathrm{H}_{25}$, and $\mathrm{C}_{14} \mathrm{H}_{29}$ were investigated. ${ }^{36}$ Again, conditions of $180{ }^{\circ} \mathrm{C}$ for 5 hours under $\mathrm{N}_{2}$ were used to synthesise spherical gold nanoparticles stabilised by alkyl groups. ${ }^{36}$ It was found that ammonium cations with one long alkyl chain are better for nanoparticle synthesis than precursors with two long alkyl chains on the ammonium. An ammonium ion with a single long alkyl chain can easily eliminate trimethylamine and supply an alkyl group to cap the gold core. ${ }^{36}$ It was found that the addition of equimolar quantities of amine to the precursor improved size regulation and allow the reaction to proceed at lower temperatures. ${ }^{36}$ The exact nature of the amine used has an effect on particle size and polydispersity. The amine, a mild reductant, reduces $\mathrm{Au}(\mathrm{I})$ to $\mathrm{Au}(0)$ inhibiting the formation of disulfide molecules. This means that thiolate ligands are present to act as capping ligands. ${ }^{36}$

Palladium. The palladium-thiolate cluster $\left[\mathrm{Pd}\left(\mathrm{SC}_{12} \mathrm{H}_{25}\right)_{2}\right]_{6}$ can act as a precursor for the synthesis of Pd nanocrystals and $\mathrm{Pd} /$ PdO core-shell particles (as well as PdS nanoparticles, see Section 3.2). ${ }^{37}$ Chemically different products were obtained using different thermolysis conditions. TGA of this precursor revealed the loss of the hydrocarbon component at around $285^{\circ} \mathrm{C}$ and the sulfur moiety at about $325^{\circ} \mathrm{C}$. When heating is carried out in air a small weight gain $(4.5 \%)$, corresponding to oxidation, is seen around $400{ }^{\circ} \mathrm{C}$. This weight gain suggests partial oxidation as it is significantly less than the value of $15 \%$ which would be expected for complete oxidation. Unsurprisingly no oxidation is observed if heating is carried out under an argon atmosphere. ${ }^{37}$ Thermolysis at $270{ }^{\circ} \mathrm{C}$ leaves the precursor unchanged whereas at a temperature of $298{ }^{\circ} \mathrm{C} \operatorname{Pd}(0)$ nanoparticles are formed. X-ray diffraction (XRD) shows that these nanoparticles are not completely crystalline and TEM imaging reveals that they are oval in shape and range in size from 13 to $22 \mathrm{~nm}$. This size polydispersity is attributed to the absence of a surfactant. On heating the precursor at $325{ }^{\circ} \mathrm{C}$ in air, core-shell $\mathrm{Pd} / \mathrm{PdO}$ particles are produced. XRD shows the fcc Pd phase and the tetragonal PdO phase. Energy filtered TEM shows a palladium core with a PdO shell. TEM images show a broad distribution of polygon shaped particles 20-100 $\mathrm{nm}$ in diameter. Even at the higher temperature of $425{ }^{\circ} \mathrm{C}$ complete oxidation does not occur. ${ }^{37}$

\subsection{Metals summary}

The melt approach has already found application in the synthesis of a range of metal nanoparticles. The metal salts of fatty acids can undergo solventless thermolysis to form self-capped silver, gold, and nickel nanoparticles. In all cases spherical particles 
with a fairly narrow size distribution were formed; interparticle separations, IR, and NMR support the idea that the particles are self-capped and that the capping ligand has the same chain length as the precursor., ${ }^{\mathbf{1 , 1 6 , 3 1}}$ The reaction temperature appears to play an important role in controlling particle size, with higher temperatures generally yielding larger particles. In the case of nickel, temperature also influences the crystal phase formed. ${ }^{21,32}$ Amines can catalyse these reactions, making them viable at reduced temperatures. ${ }^{24}$ The decomposition of silver carboxylates to form silver nanoparticles may find applications in printable polymer nanocomposites where the reaction leads to short sintering times and high conductivities. ${ }^{28}$

The metal salts of thiols have been used to synthesis silver, gold, palladium, and bismuth nanoparticles by solventless thermolysis. The decomposition mechanism involves the oxidation of the thiol to a radical and the reduction of a metal ion to its element. The radicals combine to form disulfide byproducts, which make poor capping agents explaining the polydisperse products often seen with simple metal thiolate precursors. In some cases thermolysis of the same precursor at higher temperatures yields the metal sulfide product. ${ }^{12,37}$ Precursors containing an ammonium ion with one long alkyl chain have been used in gold nanoparticle synthesis, facilitating the capping of particles with alkyl groups. Thiolate precursors often adopt layered structures which can lead to anisotropic nanoparticle growth. ${ }^{12,13}$

\section{Compound materials}

\subsection{Metal sulfide nanocrystals from dithiocarbamate precursors}

The second published account of a self-capping solventless nanoparticle synthesis came from the O'Brien group. ${ }^{2}$ An asymmetric cadmium-dithiocarbamate precursor (Fig. 5) was heated under vacuum at temperatures ranging from $150{ }^{\circ} \mathrm{C}$ to $300{ }^{\circ} \mathrm{C}$. The particles synthesised at $250^{\circ} \mathrm{C}$ were approximately $5-7 \mathrm{~nm}$ in size. IR and NMR confirm that the particles were capped with the amine $\mathrm{HNMe}\left(\mathrm{C}_{18} \mathrm{H}_{37}\right)$. The crystalline phase of the CdS particles was shown to be dependent on the thermolysis temperature: at 150-250 ${ }^{\circ} \mathrm{C} \mathrm{XRD} \mathrm{showed} \mathrm{a} \mathrm{cubic} \mathrm{phase} \mathrm{but} \mathrm{at} 300{ }^{\circ} \mathrm{C}$ the largest particles adopted the thermodynamically more stable hexagonal phase. The amount of capping agent was also shown to be temperature dependent. The particles prepared at $300{ }^{\circ} \mathrm{C}$ had significantly less capping agent that those prepared at $200^{\circ} \mathrm{C}$, as reflected in XPS $\mathrm{C} / \mathrm{Cd}$ ratios and the particles' solubility in organic solvents. ${ }^{2}$ The same group later produced the bismuth analogue of this precursor, $\mathrm{Bi}\left(\mathrm{S}_{2} \mathrm{CN}\left(\mathrm{C}_{18} \mathrm{H}_{37}\right)\left(\mathrm{CH}_{3}\right)\right)_{3}$, and heated it under vacuum for an hour at a range of temperatures from 150-

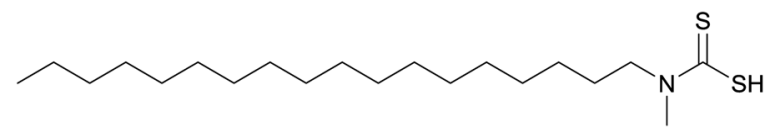

Fig. 5 The $\mathrm{Cd}$ and $\mathrm{Bi}$ complexes of this asymmetric dithiocarbamate have been used in melt reactions, yielding $\mathrm{CdS}$ and $\mathrm{Bi}_{2} \mathrm{~S}_{3}$ nanoparticles respectively. ${ }^{2,38}$
$300{ }^{\circ} \mathrm{C} .{ }^{38}$ Spherical particles of crystalline $\mathrm{Bi}_{2} \mathrm{~S}_{3}$ were produced. The particles synthesised at $250{ }^{\circ} \mathrm{C}$ were approximately $8 \mathrm{~nm}$ in diameter and showed a fairly broad size distribution. Like the cadmium analogue these particles are believed to be self-capped with $\mathrm{HNMe}\left(\mathrm{C}_{18} \mathrm{H}_{37}\right){ }^{2,38}$

Somsook et al. synthesised the cadmium-dithiocarbamate complexes shown in Fig. 6. These precursors were heated at 700 ${ }^{\circ} \mathrm{C}$ under an $\mathrm{N}_{2}$ atmosphere. ${ }^{39}$ The thermolysis residue appeared to contain both $\mathrm{CdO}$ and CdS products. Particle sizes, estimated by the Scherrer equation, were $42 \mathrm{~nm}$ for the phenyl precursor and $59 \mathrm{~nm}$ for the ferrocenyl precursor. Electron microscopy showed nanofibres were produced by the ferrocenyl precursor but not by its phenyl analogue. ${ }^{39}$

\subsection{Metal sulfide nanocrystals from the salts of thiols}

$\mathbf{B i}_{2} \mathbf{S}_{3}$. As well as being a precursor for metal nanoparticles, ${ }^{12}$ bismuth dodecanethiol can be used to synthesise $\mathrm{Bi}_{2} \mathrm{~S}_{3}$ nanostructures. When heated in air for an hour at $225^{\circ} \mathrm{C}$ the waxy precursor decomposes to produce $\mathrm{Bi}_{2} \mathrm{~S}_{3}$ nanowires. ${ }^{5}$ These nanowires are approximately $25 \mathrm{~nm}$ in diameter and many exceed $5 \mu \mathrm{m}$ in length with some as long as $70 \mu \mathrm{m}$. When additional elemental sulfur was added to the precursor $\mathrm{Bi}_{2} \mathrm{~S}_{3}$ nanorods were produced by heating for 1 hour at $160{ }^{\circ} \mathrm{C}$. The nanorods are approximately $10 \mathrm{~nm}$ in diameter and $70 \mathrm{~nm}$ in length. Both rods and wires are made of orthorhombic $\mathrm{Bi}_{2} \mathrm{~S}_{3}$ and the elongation occurs in the [002] direction. ${ }^{5}$ It is believed that addition of elemental sulfur reduces the barrier to $\mathrm{Bi}_{2} \mathrm{~S}_{3}$ nucleation. More nucleation events result in Bi depletion before extension to very long aspect ratios are reached. ${ }^{5}$ Even when elemental sulfur is added, dodecanethiol still plays an important role: if it is not present poorly formed agglomerated nanostructures are produced, presumably due to the lack of a suitable capping agent. ${ }^{5}$ At a higher thermolysis temperature $\left(240{ }^{\circ} \mathrm{C}\right)$ interwoven nanowire morphologies are observed. These structures show a high degree of orientational order with nanowires orientated perpendicular to one another forming an interlocking square lattice described as a "nanofabric". This

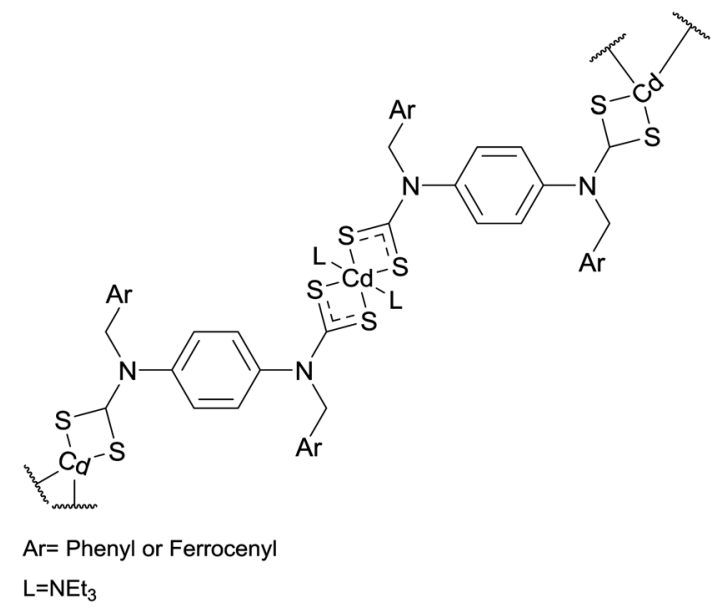

Fig. 6 Precursors used by Somsook et al. in the melt synthesis of CdS nanoparticles and nanofibres. ${ }^{39}$ 

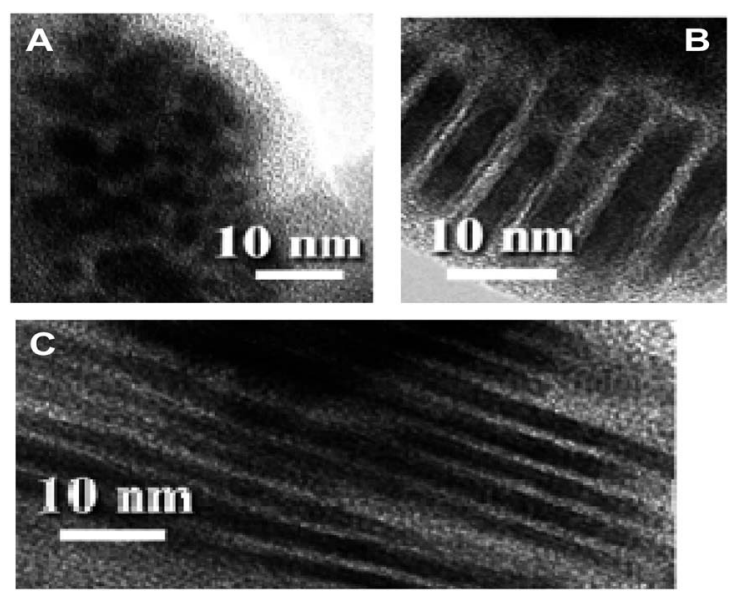

Fig. 7 Micrographs demonstrating how the extent of polymerisation in the $\mathrm{Cu}\left(\mathrm{C}_{12} \mathrm{H}_{25} \mathrm{~S}\right)_{2}$ precursor influences $\mathrm{Cu}_{2} \mathrm{~S}$ nanoproduct morphology. All are these images are from reactions carried out by heating the precursor in air at $155{ }^{\circ} \mathrm{C}$ for 120 minutes. Precursor viscosities were $<10 \mathrm{mPa} \mathrm{s}^{-1}, 13.2 \mathrm{mPa} \mathrm{s}^{-1}$, and $93.5 \mathrm{mPa} \mathrm{s}^{-1}$ for $\mathrm{A}, \mathrm{B}$, and $\mathrm{C}$ respectively. ${ }^{6}$ Adapted with permission from $\mathrm{L}$. Chen et al., J. Am. Chem. Soc., 2004, 126, 16334-16335. Copyright 2004 American Chemical Society.

NiS. The nickel analogue of the copper thiolate precursor described above has been used to synthesise NiS nanorods and triangular nanoprisms. ${ }^{4}$ The solid precursor (nickel dodecanethiol with octanoate) is heated in air at temperatures from 150 to $190{ }^{\circ} \mathrm{C}$ for times between 5 minutes and 5 hours. The researchers also experimented with the longer chain octadecanethiol in some experiments. ${ }^{4}$ Both the nanorod and nanoprism products are rhombohedral. NiS, nanorods were observed to grow in the [110] direction. XRD shows a significant amount of $\mathrm{Ni}_{3} \mathrm{~S}_{4}$ present in the products, and TEM reveals that this takes the form of misshapen rods. This by-product proved difficult to remove as the $\mathrm{Ni}_{3} \mathrm{~S}_{4}$ nanorods are a similar size to the NiS nanorods and have the same organic capping ligands. ${ }^{4}$ Fourier transform infrared spectroscopy (FTIR) revealed that the primary capping ligand is octanoate, while there was no evidence of free dodecanethiol in the products. Increasing the reaction temperature from $150{ }^{\circ} \mathrm{C}$ to $190{ }^{\circ} \mathrm{C}$ (both 1.5 hours) resulted in longer nanorods (length increasing from $19.1 \mathrm{~nm}$ to $33.6 \mathrm{~nm})$. Reaction time is also an important parameter: at short reaction times (e.g. 5 minutes) many of the particles were amorphous but longer times yielded crystalline products. A mixture of rods and triangular prisms were obtained at $190{ }^{\circ} \mathrm{C}$ for 1.5 hours whilst $190{ }^{\circ} \mathrm{C}$ for 5 hours produced a mixture of rods and quasi spherical particles. ${ }^{4}$ The particle shapes observed probably arise from the anisotropic crystal structure. Studies of thiol adsorption on copper substrates suggest that thiolate cleavage will occur at different rates on different faces of a growing nanocrystal. While less is known about thiol adsorption and cleavage on nickel surfaces, the authors speculate that some face-sensitive reactivity may be involved.,

PbS. A lead dodecanethiol precursor containing octanoate and ethylenediamine was heated at $280{ }^{\circ} \mathrm{C}$ under nitrogen for an hour producing $\mathrm{PbS}$ nanowires with high aspect ratios 
and X-shaped cross sections. ${ }^{7}$ Heating at less than $240{ }^{\circ} \mathrm{C}$ gives mostly unreacted precursor and the $\mathrm{PbS}$ formed is in the form of small round nanoparticles. Increasing the temperature produces a change from round $\mathrm{PbS}$ nanoparticles to octahedral nanocrystals and $\mathrm{PbS}$ nanowires. The octahedral particles show a tendency to adsorb to the surface of the X-shaped nanowires. XRD and EDX show that the nanowires consist of pure, single phase, PbS. ${ }^{7}$ The ethylenediamine plays the role of a capping ligand; preferential adsorption changes the growth rate of different faces. Ethylenediamine is believed to bind preferentially to the $\{111\}$ faces of the PbS rock salt structure, diminishing growth on the $\{111\}$ faces and leading to octahedral particles with large $\{111\}$ faces or nanowires extending in the [100] direction. Carrying out the reaction in the absence of the amine gives $\mathrm{PbS}$ nanocubes. When ethylenediamine is present, the optimum ratio of $\mathrm{Pb}$ to thiolate is found to be $1: 1.6$ not the expected $1: 2$ which gives uneven wires and particles. This optimum precursor is found (from the lattice spacing of the layered solid) to contain two lead salts: lead dodecanethiol and lead octanoate. The lead thiolate is the source of $\mathrm{PbS}$, while the lead octanoate appears to play a role in controlling morphology. ${ }^{7}$

PdS. Heating the palladium-thiolate cluster $\left[\mathrm{Pd}\left(\mathrm{SC}_{12} \mathrm{H}_{25}\right)_{2}\right]_{6}$ at $430{ }^{\circ} \mathrm{C}$ in an Argon atmosphere yields PdS nanoparticles. XRD has shown these to be highly crystalline, adopting the tetragonal phase. TEM imaging reveals they are spherical in shape and are $9.2 \pm 0.9 \mathrm{~nm}$ in size. ${ }^{37}$ This same precursor forms Pd nanoparticles (see Section 1.2) when the reaction is carried out at a lower temperature of $298{ }^{\circ} \mathrm{C}$.

\subsection{Metal sulfide nanoparticles from dithiocarboxylate precursors}

The metal dithiocarboxylates $\mathrm{M}\left(\mathrm{S}_{2} \mathrm{CAr}\right)_{2}$ (tmeda) $(\mathrm{Ar}=\mathrm{Ph}$, Tol) $(\mathrm{M}=\mathrm{Cd}, \mathrm{Zn}, \mathrm{Hg})\left(\mathrm{tmeda}=\left(\mathrm{CH}_{3}\right)_{2} \mathrm{NCH}_{2} \mathrm{CH}_{2} \mathrm{~N}\left(\mathrm{CH}_{3}\right)_{2}\right)$ have been used to synthesise metal sulfide nanoparticles by solventless thermolysis. The precursors were heated at $350{ }^{\circ} \mathrm{C}$ for 2 hours under nitrogen. The CdS nanoproducts adopted the hexagonal crystalline phase, while the HgS and ZnS nanoparticles were shown to adopt the cubic phase. ${ }^{41}$ Increased reaction temperature increased particle size; the pyrolysis of the $\mathrm{M}=\mathrm{Cd}, \mathrm{Ar}=\mathrm{Ph}$ precursor at 300,400 , and $500{ }^{\circ} \mathrm{C}$ gave $\mathrm{CdS}$ particles with particle sizes (estimated from the Scherrer equation) of 18, 36 and $43 \mathrm{~nm}$ respectively. ${ }^{41}$

\subsection{Metal sulfide nanocrystals from xanthate precursors}

Singhal et al. used an allyl-palladium(II)-xanthate complex and a palladium(II)-xanthate complex (Fig. 8) as single-source precursors for PdS nanoparticle synthesis. ${ }^{42}$ The precursors were heated in a furnace at $300{ }^{\circ} \mathrm{C}$ under an argon atmosphere. a)

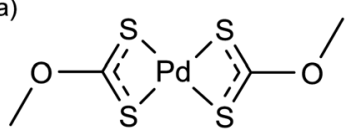

b)

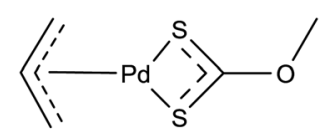

Fig. 8 Palladium-xanthate precursors used in the solventless synthesis of PdS nanoparticles. ${ }^{42}$
XRD showed the products to be crystalline tetragonal PdS. The two complexes shown in Fig. 8a and b gave particle sizes, estimated using the Scherrer equation, ${ }^{43}$ of $32 \mathrm{~nm}$ and $16 \mathrm{~nm}$ respectively. ${ }^{42}$

\subsection{Metal sulfides from the salts of thiotetrazoles}

The cadmium salts of 1-substituted-5-thiotetrazoles (Fig. 1f) can be used as a single-source precursors to form CdS nanoparticles capped with thiotetrazoles. ${ }^{\mathbf{4 4}}$ Two precursor were heated at a rate of $5{ }^{\circ} \mathrm{C} \mathrm{min}^{-1}$ under a flow of nitrogen gas. The ethyl precursor was held at $250{ }^{\circ} \mathrm{C}$ for 1 hour whilst the adamantyl precursor was held at $250{ }^{\circ} \mathrm{C}$ for 2 hours. These reactions produced spherical CdS nanoparticles $2.5-3 \mathrm{~nm}$ in diameter. IR spectroscopy confirms the presence of thiotetrazolate anions on the nanoparticles' surfaces. The self-capping nature of the reaction is reflected in the solubility of the products: the ethyl precursor gives nanoparticles that are soluble in acetonitrile but not hexane, whilst the adamantyl gave particles soluble in hexane but not acetonitrile. ${ }^{\mathbf{4 4}}$ Thiotetrazolates are potentially useful capping ligands because they decompose to give gaseous products. While capping ligands are vital in achieving monodispersity, preventing aggregation, and making nanoparticles dispersible in organic solvents, they are usually difficult to remove completely. Heating tetrazolate capped nanoparticles at 250-270 ${ }^{\circ} \mathrm{C}$ for $1.5-2$ hours gives a solid product that is insoluble in organic solvent. IR spectroscopy shows no tetrazolate remains associated with the solid and it is believed that the tetrazolate ligand decomposes to give gaseous products $\left(\mathrm{RN}_{3}\right.$, $\mathrm{CS}_{2},(\mathrm{CN})_{2}$ and $\mathrm{N}_{2}$ ) leaving uncapped nanoparticles behind. ${ }^{44}$

\subsection{Metal chalcogenides from silyl precursors}

DeGroot et al. investigated the solventless thermal decomposition of four single-source precursors for zinc chalcogenide synthesis: (1) $\left(N, N^{\prime} \text {-tmeda)Zn( } \mathrm{SSiMe}_{3}\right)_{2}$, (2) $\left(N, N^{\prime}\right.$-tmeda)Zn(Se-

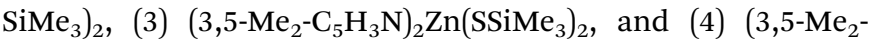
$\left.\mathrm{C}_{5} \mathrm{H}_{3} \mathrm{~N}\right)_{2} \mathrm{Zn}\left(\mathrm{SeSiMe}_{3}\right)_{2} \cdot{ }^{45}$ TGA reveals that complete thermal decomposition of these complexes occurs at $<300{ }^{\circ} \mathrm{C}$. Unsurprisingly the sulfur complexes are more stable than their selenium counterparts. Heating up to $700{ }^{\circ} \mathrm{C}$ achieved complete thermolysis, producing bulk $\mathrm{ZnE}(\mathrm{E}=\mathrm{S}$, Se). ZnS was shown to adopt the hexagonal wurtzite phase while ZnSe adopted the cubic sphaleritic phase. Heating to $200{ }^{\circ} \mathrm{C}$ avoided the loss of the nitrogen donor ligands, which act as capping ligands, and lead to the formation of nanoparticles. XRD of the $200{ }^{\circ} \mathrm{C}$ thermolysis product shows that $\mathrm{ZnE}$ is produced and peak broadening suggested that the material formed nanoparticles. This suggestion is supported by UV spectra of the thermolysis products of 1 and 2, which show the band gaps shifted to higher energies relative to the bulk. However, the decomposition products of 3 and 4 at $200{ }^{\circ} \mathrm{C}$ show no such quantum confinement effects, implying larger particles. ${ }^{45}$

\subsection{Metal oxide nanocrystals from the salts of carboxylic acids}

Iron(II)-oleate can be used as a precursor for solventless synthesis of $\mathrm{Fe}_{3} \mathrm{O}_{4}$ nanoparticles. ${ }^{19}$ The solid precursor was 
placed in a Pyrex tube which was flushed with nitrogen and sealed under low pressure. The tube was then heated to $320{ }^{\circ} \mathrm{C}$ and held at this temperature for two hours. The resulting $\mathrm{Fe}_{3} \mathrm{O}_{4}$ nanoparticles were spherical in shape, highly crystalline and showed a narrow size distribution, with an average diameter of $10.6 \pm 1.2 \mathrm{~nm}$. The nanoparticles were found to be capped with oleate ligands. The spherical nanoparticles can assemble into close-packed two-dimensional arrays, the spacing between nanoparticles was observed to be $2 \mathrm{~nm}$, significantly less than twice the length of the oleate chain, suggesting interdigitation. ${ }^{19}$ Particle size and morphology was found to depend on temperature, annealing time, and pressure. Particle size increases with reaction time and particles annealed for longer than 3 hours become irregularly shaped. TGA reveals that the precursor decomposition temperature is pressure dependent. The decomposition temperatures increase under higher pressures. Whilst the reaction at 300 mTorr gave uniform spherical particles, the reaction at 500 mTorr give a mixture of morphologies with spheres, trigonal prisms, rods, and 'diamond' shaped particles all present. ${ }^{19}$ The authors suggest that the higher decomposition temperature at 500 mTorr leads to slower nucleation and consequently more morphological variety. ${ }^{\mathbf{1 9}}$

The above reaction has also been used as the first step in a two stage synthesis of magnetic iron nanoparticles. The Fe(II) salt of oleic acid is heated at $400{ }^{\circ} \mathrm{C}$ under a reduced pressure of 240 mTorr for 2 hours forming oleate capped $\mathrm{Fe}_{3} \mathrm{O}_{4}$ nanoparticles. TEM images of these particles show them to be roughly 18 to $24 \mathrm{~nm}$ in diameter. The iron oxide nanoparticles were then mixed with $\mathrm{NaCl}$ in a ratio of $1: 40$, ball milled to produce a fine powder and heated at $700{ }^{\circ} \mathrm{C}$ under an $\mathrm{Ar}-\mathrm{H}_{2}$ gas mixture. The hydrogen gas reduced $\mathrm{Fe}_{3} \mathrm{O}_{4}$ to $\mathrm{Fe}$, forming ferrite nanoparticles. ${ }^{\mathbf{4 6}}$

$\mathrm{PbCl}-$ oleate has been used as a precursor for the solventless synthesis of $\mathrm{Pb}_{3} \mathrm{O}_{2} \mathrm{Cl}_{2}$ nanobelts. ${ }^{47}$ The solid precursor is heated in air for an hour at $190{ }^{\circ} \mathrm{C}$; decomposition is believed to occur via the cleavage of the $\mathrm{C}-\mathrm{O}$ bond in the oleate. The nanobelts produced have the mendipite crystal structure. In $90 \%$ of cases the nanobelt is elongated in the [010] direction. This elongation reflects the underlying crystal structure: accommodating the continuation of $\mathrm{O}_{2} \mathrm{~Pb}_{3}$ chains along the length of the nanobelt. The belts are 29-170 nm wide, an average of $23.3 \mathrm{~nm}$ thick, and $>4 \mu \mathrm{m}$ long. ${ }^{47}$ The nanobelts are dispersible in non-polar organic solvents and it seems most likely that they are capped by alkyl groups formed in the decomposition process. The addition of ethylenediamine to the precursor improves the yield of nanobelts. Without this addition nanobelts elongated in the [010] direction are still produced, but nanocrystals roughly $5 \mathrm{~nm}$ in diameter are also formed. ${ }^{47}$

Thermolysis of the molecular cluster $\mathrm{Mn}_{12} \mathrm{O}_{12}\left(\mathrm{O}_{2} \mathrm{C}-\right.$ $\mathrm{R})_{16}\left(\mathrm{H}_{2} \mathrm{O}\right)_{4}$ gives $\mathrm{MnO}$ nano- and micro-products. Product size and morphology is found to depend on the temperature and time of thermolysis as well as the carboxylic acid employed. ${ }^{48}$ Heating of the precursor $\left(\mathrm{R}=\mathrm{C}_{6} \mathrm{H}_{5}\right)$ at $400{ }^{\circ} \mathrm{C}$ for 10 hours gives crystalline $\mathrm{MnO}$ nanoparticles $70 \mathrm{~nm}$ in diameter and spherical in shape. Higher temperatures give larger structures, for example heating at $500{ }^{\circ} \mathrm{C}$ for 10 hours produces pyramid shaped $\mathrm{MnO}$ particles $0.12 \mu \mathrm{m}$ in diameter. ${ }^{48}$

\subsection{Compounds materials summary}

Nanocrystals of $\mathrm{ZnS}, \mathrm{CdS}, \mathrm{HgS}, \mathrm{Bi}_{2} \mathrm{~S}_{3}, \mathrm{Cu}_{2} \mathrm{~S}$, NiS, PbS, PdS, $\mathrm{Fe}_{3} \mathrm{O}_{4}, \mathrm{MnO}$, and $\mathrm{Pb}_{3} \mathrm{O}_{2} \mathrm{Cl}_{2}$ have been synthesised by melt methods. A wider range of precursor chemistry has been applied to the synthesis of compound materials than to metals. The metal salts of fatty acids and thiols have been successfully used as precursors to both metal and compound nanoparticles. For some thiol salts the same precursor can yield either the metal or its sulfide, the compound forming at a higher reaction temperature. ${ }^{5,11,37}$ Ligands like dithiocarbamates and xanthates are already well established as single-source precursors in hotinjection syntheses and MOCVD. ${ }^{15,49}$ The successful application of these precursors to the melt approach suggests that the literature on MOCVD and hot-injection synthesis may contain a rich vein of promising single-source precursors as yet unused in melt reactions. ${ }^{\mathbf{1 4 , 1 5}}$

The complexes used as precursors can be divided into two classes: those where a single ligand acts as both the source of the anion and the capping ligand; and those where the metal ion is complexed to more than one type of ligand, one having the role of anion source the other acting solely as a capping agent. An example of the former would be the synthesis of CdS nanoparticles from a cadmium-dithiocarbamate precursors; whilst an example of the latter case would be the thermolysis of $\left(N, N^{\prime}\right.$-tmeda) $\mathrm{Zn}\left(\mathrm{SSiMe}_{3}\right)_{2}$, where $\mathrm{SSiMe}_{3}$ provides the sulfide but the amine is believed to cap the $\mathrm{ZnS}$ nanoparticles. ${ }^{2,45}$ In addition to conventional coordination complexes, molecular clusters have also been used as precursors in melt reaction. ${ }^{37,48}$

\section{Concluding remarks}

Abe and co-workers were apparently the first to report the potential practical importance of the melt approach to nanoparticle synthesis. ${ }^{1}$ The method attracted some attention, due mainly to its possible commercial applications as a route to novel silver solder, ${ }^{28,29}$ but the huge potential of this approach is yet to be more generally recognised. In the intervening years, the range of metal, metal chalcogenide and metal oxide nanocrystals synthesised in melt reactions has expanded, as has the precursor chemistry used. However, in many respects this is still a nascent field, the level of mechanistic understanding that has been developed for hot injection and heating up approaches is much greater. ${ }^{50}$ When compared to more established areas such as MOCVD and the hot-injection approach, relatively few singlesource precursors have been investigated. There are also whole classes of compounds that have yet to be synthesised by this approach e.g. the III-V semiconductors.

Melt reactions potentially offer the chemist precise control over a number of reaction parameters. These can be used to influence nanoparticle size, shape and chemistry. Higher temperatures typically lead to larger particles., ${ }^{\mathbf{4 , 9 , 1 9 , 3 2 , 4 1 , 4 8}}$ Different temperatures can also yield different phases or materials ${ }^{5,11,32,37}$ and different particle shapes. ${ }^{3,5}$ Thiolate precursors react via $\mathrm{M}-\mathrm{S}$ bond cleavage at lower temperatures to give metal nanoparticles whilst at higher temperatures $\mathrm{S}-\mathrm{C}$ bond cleavage occurs, giving the sulfide.,11,37 Extended reaction 
time can also have a pronounced effect on morphology, for example the evolution of nanofilms into nanorhombi ${ }^{12}$ or spheres into platelets. ${ }^{9}$ In some cases changes in the atmosphere under which the reaction is carried out can apparently change product morphology. ${ }^{31}$

The melt approach also offers some novel ways in which the size and shape of nanoproducts can be controlled. The layered structure of silver and bismuth thiolates appear to encourage anisotropic nanocrystal growth. ${ }^{\mathbf{8 1 2 , 1 3}}$ In the synthesis of $\mathrm{Cu}_{2} \mathrm{~S}$ nanostructures, it has been shown that the extent of polymerisation in copper-thiolate precursor dictates the product morphology. ${ }^{6}$ Work on the iron salts of fatty acids has demonstrated that the pressure under which thermolysis occurs can alter the morphology of the $\mathrm{Fe}_{3} \mathrm{O}_{4}$ nanoparticles formed. ${ }^{19}$

As well as offering new ways to control shape, solventless synthesis has a number of practical advantages: the precursors are easy to handle, the need for harsh reactants such as reducing agents or sulfonating agents is eliminated, and the reaction parameters (temperature and time of thermolysis) are easily controlled. The process of heating a precursor in a furnace should be relatively easy and cheap to scale up. The fact that melt reactions are solventless and, often, self-capping, means the solvents and capping agents employed in traditional nanoparticle synthesis are not needed and we note that the yields of these reactions are often very high. For these reasons the melt approach has the potential to provide an economical means of mass producing nanocrystals.

\section{Acknowledgements}

This work was supported by the Engineering and Physical Sciences Research Council (UK) and the North West Nanoscience Doctoral Training Centre (NOWNano DTC) at the University of Manchester.

\section{Notes and references}

1 K. Abe, T. Hanada, Y. Yoshida, N. Tanigaki, H. Takiguchi, H. Nagasawa, M. Nakamoto, T. Yamaguchi and K. Yase, Thin Solid Films, 1998, 327-329, 524.

2 M. Lazell and P. O’Brien, Chem. Commun., 1999, 2041.

3 T. H. Larsen, M. Sigman, A. Ghezelbash, R. C. Doty and B. A. Korgel, J. Am. Chem. Soc., 2003, 125, 5638.

4 A. Ghezelbash, M. B. Sigman and B. A. Korgel, Nano Lett., 2004, 4, 537.

5 M. B. Sigman and B. A. Korgel, Chem. Mater., 2005, 17, 1655. 6 L. Chen, Y. B. Chen and L. M. Wu, J. Am. Chem. Soc., 2004, 126, 16334.

7 J. Chen, L. Chen and L.-M. Wu, Inorg. Chem., 2007, 46, 8038. 8 Y.-B. Chen, L. Chen and L.-M. Wu, Inorg. Chem., 2005, 44, 9817.

9 M. B. Sigman, A. Ghezelbash, T. Hanrath, A. E. Saunders, F. Lee and B. A. Korgel, J. Am. Chem. Soc., 2003, 125, 16050.

10 C. B. Murray, D. J. Norris and M. G. Bawendi, J. Am. Chem. Soc., 1993, 115, 8706.

11 J. Park, K. J. An, Y. S. Hwang, J. G. Park, H. J. Noh, J. Y. Kim, J. H. Park, N. M. Hwang and T. Hyeon, Nat. Mater., 2004, 3,
891; M.-Y. Chiang, S.-H. Chang, C.-Y. Chen, F.-W. Yuan and H.-Y. Tuan, J. Phys. Chem. C, 2011, 115, 1592.

12 J. Chen, L.-M. Wu and L. Chen, Inorg. Chem., 2007, 46, 586. 13 L. Chen and L.-M. Wu, in Inorganic Chemistry in Focus III, Wiley-VCH Verlag GmbH \& Co. KGaA, 2006, pp. 295-303.

14 M. A. Malik, M. Afzaal and P. O'Brien, Chem. Rev., 2010, 110, 4417; D. Fan, M. Afzaal, M. A. Mallik, C. Q. Nguyen, P. O'Brien and P. J. Thomas, Coord. Chem. Rev., 2007, 251, 1878; M. A. Malik, N. Revaprasadu and P. O'Brien, Chem. Mater., 2001, 13, 913; N. L. Pickett and P. O'Brien, Chem. Rec., 2001, 1, 467.

15 P. O’Brien, J. R. Walsh, I. M. Watson, M. Motevalli and L. Henriksen, J. Chem. Soc., Dalton Trans., 1996, 2491-2496.

16 K. Abe, Y. Ichino, N. Takada, T. Hanada, Y. Yoshida, N. Tanigaki, T. Yamaguchi, H. Nagasawa and K. Yase, Mol. Cryst. Liq. Cryst. Sci. Technol., Sect. A, 1999, 337, 31.

17 H. Nagasawa, M. Maruyama, T. Komatsu, S. Isoda and

T. Kobayashi, Phys. Status Solidi A, 2002, 191, 67.

18 D. K. Lee and Y. S. Kang, ETRI Journal, 2004, 26, 252.

19 H. G. Cha, D. K. Lee, Y. H. Kim, C. W. Kim, C. S. Lee and Y. S. Kang, Inorg. Chem., 2008, 47, 121.

20 N. Yang and K. Aoki, J. Phys. Chem.B, 2005, 109, 23911.

21 M. Cavicchioli, L. C. Varanda, A. C. Massabni and P. Melnikov, Mater. Lett., 2005, 59, 3585.

22 M. Yamamoto and M. Nakamoto, J. Mater. Chem., 2003, 13, 2064.

23 Y. Kashiwagi, M. Yamamoto and M. Nakamoto, J. Colloid Interface Sci., 2006, 300, 169.

24 M. Pecht, Y. Fukuda and S. Rajagopal, IEEE Trans. Electron. Packag. Manuf., 2004, 27, 221.

25 Y. Li, K. S. Moon and C. P. Wong, Science, 2005, 308, 1419.

26 H. J. Jiang, K. S. Moon, J. X. Lu and C. P. Wong, J. Electron. Mater., 2005, 34, 1432.

27 Y. Li and C. P. Wong, Mater. Sci. Eng., 2006, 51, 1; H. J. Jiang, K. S. Moon, Y. Li and C. P. Wong, Chem. Mater., 2006, 18, 2969.

28 R. W. Zhang, W. Lin, K. S. Moon and C. P. Wong, ACS Appl. Mater. Interfaces, 2010, 2, 2637.

29 M. Jakubowska, M. Jarosz, K. Kielbasinski and A. Mlozniak, Microelectron. Reliab., 2011, 51, 1235.

30 P. V. Asharani, Y. L. Wu, Z. Y. Gong and S. Valiyaveettil, Nanotechnology, 2008, 19, 255102; E. Navarro, F. Piccapietra, B. Wagner, F. Marconi, R. Kaegi, N. Odzak, L. Sigg and R. Behra, Environ. Sci. Technol., 2008, 42, 8959; J. Y. Roh, S. J. Sim, J. Yi, K. Park, K. H. Chung, D. Y. Ryu and J. Choi, Environ. Sci. Technol., 2009, 43, 3933; T. M. Tolaymat, A. M. El Badawy, A. Genaidy, K. G. Scheckel, T. P. Luxton and M. Suidan, Sci. Total Environ., 2010, 408, 999.

31 M. Yamamoto and M. Nakamoto, Chem. Lett., 2003, 32, 452. 32 S. G. Kim, Y. Terashi, A. Purwanto and K. Okuyama, Colloids Surf., A, 2009, 337, 96.

33 Y. Wang, J. Chen, L. Chen, Y.-B. Chen and L.-M. Wu, Cryst. Growth Des., 2010, 10, 1578.

34 G. Carotenuto, C. L. Hison, F. Capezzuto, M. Palomba, P. Perlo and P. Conte, J. Nanopart. Res., 2009, 11, 1729.

35 M. Nakamoto, M. Yamamoto and M. Fukusumi, Chem. Commun., 2002, 1622.

36 M. Nakamoto, Y. Kashiwagi and M. Yamamoto, Inorg. Chim. Acta, 2005, 358, 4229. 
37 D. Jose and B. R. Jagirdar, J. Solid State Chem., 2010, 183, 2059.

38 M. Lazell, S. J. Norager, P. O’Brien and N. Revaprasadu, Mater. Sci. Eng., C, 2001, 16, 129.

39 N. Thammakan and E. Somsook, Mater. Lett., 2006, 60, 1161.

40 A. E. Saunders, A. Ghezelbash, D.-M. Smilgies, M. B. Sigman, Jr and B. A. Korgel, Nano Lett., 2006, 6, 2959.

41 G. Kedarnath, V. K. Jain, S. Ghoshal, G. K. Dey, C. A. Ellis and E. R. T. Tiekink, Eur. J. Inorg. Chem., 2007, 1566.

42 A. Singhal, D. P. Dutta, A. K. Tyagi, S. M. Mobin, P. Mathur and I. Lieberwirth, J. Organomet. Chem., 2007, 692, 5285.

43 A. L. Patterson, Phys. Rev., 1939, 56, 978.

44 S. V. Voitekhovich, D. V. Talapin, C. Klinke, A. Kornowski and H. Weller, Chem. Mater., 2008, 20, 4545.

45 M. W. DeGroot, C. Khadka, H. Rosner and J. F. Corrigan, J. Cluster Sci., 2006, 17, 97.
46 Y. C. Han, H. G. Cha, C. W. Kim, Y. H. Kim and Y. S. Kang, J. Phys. Chem. C, 2007, 111, 6275.

47 M. B. Sigman and B. A. Korgel, J. Am. Chem. Soc., 2005, 127, 10089.

48 L. Y. Chen, H. Xing, Y. M. Shen, J. F. Bai and G. Q. Jiang, J. Solid State Chem., 2009, 182, 1387.

49 P. O’Brien, J. R. Walsh, I. M. Watson, L. Hart and S. R. P. Silva, J. Cryst. Growth, 1996, 167, 133; J. Akhtar, M. Afzaal, M. A. Vincent, N. A. Burton, I. H. Hillier and P. O’Brien, Chem. Commun., 2011, 47, 1991; B. Ludolph, M. A. Malik, P. O'Brien and N. Revaprasadu, Chem. Commun., 1998, 1849.

50 C. de Mello Donegá, P. Liljeroth and D. Vanmaekelbergh, Small, 2005, 1, 1152; S. G. Kwon, Y. Piao, J. Park, S. Angappane, Y. Jo, N.-M. Hwang, J.-G. Park and T. Hyeon, J. Am. Chem. Soc., 2007, 129, 12571. 